\title{
Distributed power generation and power supply reliability improvement
}

\author{
Felix Byk $^{1}$, Yuri Kakosha ${ }^{1}$ and Lyudmila Myshkina ${ }^{1 *}$ \\ ${ }^{1}$ Novosibirsk state technical university, Karla Marksa, 20, Novosibirsk, Russia
}

\begin{abstract}
The appearance of distributed generation in the power supply systems of industrial enterprises leads to the emergence of requirements for networks to increase their redundancy functions. The introduction of network redundancy fees will lead to an increase in electricity supply costs for such enterprises. The source of additional revenue may be the provision of regulatory resources to the aggregator of electricity demand management in the UES of Russia. But this requires changes that allow active consumers to supply the distribution network with excess capacity during peak hours in the UES of Russia. The article shows the efficiency of operation in the mode without power supply to the distribution network. This mode does not lead to a decrease in revenues from network services for the transmission of electricity. The proposed changes will lead to an increase in the reliability of power supply and increase the economic efficiency of the UES of Russia.
\end{abstract}

\section{Introduction}

Historically, the massive emergence of distributed power generation in Russia was initiated by high requirements to reliability of power supply to healthcare institutions, water intakes, boiler houses, sewage pumping stations, sports complexes, airports, facilities of the Ministry of Emergency Situations, and, of course, continuous cycle enterprises of chemical and nuclear industries.

Traditionally, standby diesel generator sets (DGS) and then gas-powered generator sets (GGS) were used as distributed generation (DG) facilities. They are equipped with various automatics starting with automatic transfer switch. The range of generators for redundancy in the electrical distribution network is wide, and they differ in the degree of their automation. With the 3rd degree of automation, the unattended operation time is more than 150 hours.

The difference between standby units is their relatively low power and high cost of electricity produced by DGS - more than $18 \mathrm{RUB} / \mathrm{kWh}$. They are unable to activate instantly; the start delay can be from 2 to 15 seconds. This often does not meet the requirements of particularly time-sensitive equipment. To avoid this, uninterruptible power supply units (UPS) are used in conjunction with an emergency generator to maintain the power supply in this period of time.

Now that technologies have caught on, various UPSs have emerged, but the most common are lithium-ion batteries. Their use as a backup has become mandatory in the power supply of information systems for data collecting and processing, for example, in banks, in process control automation systems created on a microprocessor base, for example, at enterprises providing communication services, etc. The advantage of lithium-ion storage devices is their good start-stop characteristics and relatively low power cost. At present, such UPSs are used at large substations of Rosseti FGC UES PJSC to ensure uninterrupted power supply to automated dispatch management systems, relay protection and emergency automation, and starting units and executive devices of switching equipment.

Against the background of a significant difference in the costs of technological connection of consumers of first and second categories of reliability, the relevance of a backup energy source availability increases. There are examples when a $12 \mathrm{MW}$ GGS was installed to perform the functions of centralized power supply redundancy. It is obvious that the costs of installing backup generators bring to an increase in reliability, but reduce the economic efficiency of the power supply system of enterprises.

Therefore, many enterprises, where GGSs are installed as emergency sources, have decided to transfer standby units to the operating power source mode, and transfer the backup function to the centralized power supply system. With a lack of DG capacities, a combined two- and three-way power supply is carried out, which increases not only the reliability, but also the efficiency of power supply under cross-subsidization conditions.

In truth, power supply systems are being created at enterprises that use their own power sources of various capacities, capable of being in working condition for a long time and working in the "following the load" mode. In various sources [1-4] it is proposed to divide the given distributed generation facilities by their capacity into three groups: micro-generation with units up to $100 \mathrm{~kW}$, mini-generation with units from $100 \mathrm{~kW}$ to $1 \mathrm{MW}$, small

\footnotetext{
* Corresponding author: Lsmyshkina@gmail.com
} 
generators with units from $1 \mathrm{MW}$ to $10 \mathrm{MW}$. Different countries set their own "top-down" restrictions for the capacity of multi-unit power plants on the units of each group.

In Russia, sources with a capacity of up to $5 \mathrm{MW}$ can be classified as mini-power plants, and sources with a capacity of up to $25 \mathrm{MW}$ can be classified as low-power plants. This kind of classification is not established in standards, but it reflects differences between these stations specified in the technological regulations for connection to the networks and in the rules for providing information for the implementation of operational dispatch control in the electric power industry. An important difference between mini and small generation units is the value of their generator voltage, which affects technical solutions for their technological connection.

Thus, enterprises in various sectors of economics solve the problem of increasing the reliability and efficiency of power supply, carrying out technological connection of the third category of reliability, but at the same time they have a second independent power source [5] There is an obvious benefit for enterprises from reducing the cost of electricity received from a centralized power supply system, the cost of which is significantly higher than the cost of electricity from their own GGS or GTG. It should be noted that the costs of maintaining standby generators in good working order are comparable to the costs of maintaining them in operation condition. The development of a fleet life under load of generators, of course, requires maintenance and repairs, but economic effects received by the enterprise doing it without additional costs of the main production, as opposed to sources of similar costs with relation to standby generators.

The focus chosen by industrial enterprises on creation of power supply systems based on distributed generation is obvious. This is explained by the fact that large enterprises have their own networks that form a power supply scheme, and a land plot sufficient to accommodate distributed generation power plants. With the existing final electricity prices, the payback period of energy sources, depending on their loading conditions, is 3 to 5 years that determines the feasibility of capital investments in the enterprise's energy system development.

\section{Local power systems}

In the literature there are various designations for such local power systems (LES) created on the basis of distributed generation - MicroGrid, MiniGrid, Energy Cell $[2,3,6]$. However, it is difficult to find an unambiguous classification to understand common differences between them. Therefore, in this article, MicroGrid is understood as a distributed energy facility (DEF) created on the basis of micro- or mini-generation connected to a low voltage electrical network.

It is proposed to refer DEF created on the basis of distributed generation connected to medium voltage distribution networks to MiniGrid. They are included in the power district reducing the local power deficit. Energy Cell is a redundant or load and generation balanced MiniGrid. Energy Cell can operate autonomously (isolatedly) with the required level of balance and operating reliability, with standard uninterrupted power supply to its consumers.

Standards and requirements for Energy Cell connection to the grid of the energy district should be established by consumers and the regional grid organization, district dispatch office and the last resort supplier.

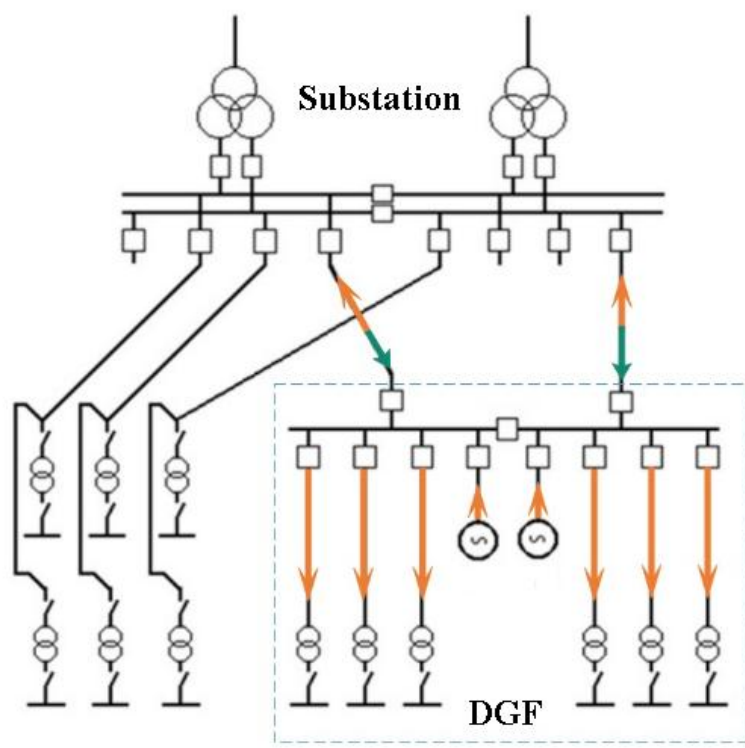

Fig. 1. Scheme of DEF connection to the power district grids.

MiniGrid and Energy Cell creation in Russia is mainly based on generation that runs on natural gas, associated petroleum gas, landfill and blast furnace gas, as well as on products from industrial, agricultural and household waste. They may include renewable energy generators and energy storage systems.

An accurate assessment of distributed generation share as well as the dynamics of its change in the Russian energy sector is rather difficult. There are still power plants in the "grey" zone operating as part of power supply systems of industrial consumers that do not supply electricity to the UES of Russia. According to experts [2, 5], the gross installed capacity of power plants up to $25 \mathrm{MW}$ is $12-17 \mathrm{GW}$, some of which serve as electricity sources in isolated power systems. According to information from oil producing companies, they have more than 100 power plants with a total capacity of about $2 \mathrm{GW}$. As an example, we can point to the Government's decision to create industrial MiniGrid called the Active Energy Complex for enterprises based on generation up to $25 \mathrm{MW}[7,8]$.

It is to be noted that groundbreaking changes in the development of distributed generation in the constituent entities of the Federation [9] became possible due to the achieved and planned level of gasification in the country, which radically changes the fuel landscape in the provinces. With the advent of an extensive gas pipeline system, an alternative to the electric grid complex arose, since gasification creates favourable conditions for 
electric energy production in the immediate vicinity of consumers. Therefore, the development of Russian distributed energy generation will be aimed at creating the MiniGrid and Energy Cell on the basis of small distributed generation on natural gas, with their integration into regional power supply systems.

The development of these DEF's is stimulated by a decrease in availability of technological connection and uninterrupted power supply of consumers from a centralized power supply system, a constant increase in the network component in the final cost of electricity [10]. The Russian concept of energy transition to distributed generation is aimed at improving the technical and economic efficiency of production processes and transmission of electric energy. At the same time, the processes should be controlled by automatic systems created on the basis of SMART Grid solutions that ensure decentralization of control over the functioning of MiniGrid and Energy Cell [1, 2, 6].

In some constituent entities of the Federation concepts and programs for the development of distributed energy based on distributed generation are being developed, including those working on renewable energy sources. The main objectives of these documents are to attract private investment in the regional electric power industry to improve the reliability and quality of power supply and stabilize the rate of growth in the price of electricity for consumers.

However, the process of implementing regional plans is met with opposition from the well-known triad - the regional territorial grid organization (RGC) as a subdivision of Rosseti PJSC, the regional dispatch department (RDD) as a branch of System Operator PJSC, and a last resort supplier as energy sales organization performing the functions of a retail market operator. They see certain risks for themselves from the emergence of DEFs, including the loss of control and management of the development and functioning of the regional electric power industry. RGCs concern about a drop in income caused by a decrease in the volume of electricity transmission and a reduction in investment in the development of the grid complex, RDDs are uncomfortable with appearance of decentralized control elements and increase in the variety of circuit-mode conditions that complicate the work of RDDs, and last resort suppliers - with the appearance at the retail market of independent competitive electricity suppliers capable to draw away some consumers.

The above mentioned entities rely on numerous regulatory legal acts of various kinds, have a huge influence on regional executive and legislative authorities. They always reckon on and have support at the federal level, because the state is usually their main owner. Their focus on traditional technologies and preservation of the existing organizational structure limit the implementation of scientific and technological progress achievements, hinder the transition to innovative development of the electric power industry. Therefore, the main direction for the energy transition is to consider the creation of favourable conditions for the emergence of appropriate DEFs. Currently, the priority is to improve legislation and eliminate administrative barriers.

Obviously, the basis of the distributed generation should be technical means for production and storage of electricity. Besides, technological solutions are needed for a harmonious combination of decentralized and centralized control systems for operation and development of power supply systems, which is impossible without digitalization of the electric power industry.

\section{Effects of creating local power systems}

In this respect much has been done and continues to be done within the framework of the EnergyNet NTI "road map" adopted by the government. But it is necessary to determine which direction of DEF development brings the maximum effect, and not for an individual enterprise, but for the entire regional power supply system. It is important to have unambiguous and generally accepted criteria that pave the way for new technical solutions and technologies that allow extracting useful and significant effects in the interests of consumers, ensuring the socioeconomic development of districts, regions, and the country as a whole.

It is these effects that should be classified as systemic, even if they contradict the interests of large generating and grid companies. As such a criterion, it is proposed to evaluate the influence of DEFs on improving the reliability and availability of power supply. The greater is the number of consumers with indicated properties increased, the greater systemic effect this DEF brings.

In Russia, the number of industrial MiniGrid has grown significantly over the past $8-10$ years. There are numerous examples of this. But RGC and RDD, as a rule, make a requirement to such enterprises - they are not allowed to supply electric power and energy to the external grid. This obviously reduces the value of the installed power source capacity, which provides independent two- and three-way power supply for increased reliability. In addition, the economic efficiency of the small distributed generation operation decreases, especially for a consumer with a high uneven load schedule.

Besides, the creation of scarce industrial MiniGrids negatively affects the cost of electricity for other consumers of the energy district. It is obvious that with the advent of MiniGrids at individual enterprises, the transmission tariff increase for everyone else. This is explained by a decrease in the volume of electricity transmission through RGC networks and an increase in the load of cross-subsidization for the remaining industrial consumers. One more negative point should be noted too. Creation of industrial MiniGrids changes the structure of power consumption in the power district, because with industrial enterprises shifting away from centralized power supply, the proportion of utility and non-industrial consumers increases. Naturally, this affects the configuration of daily load schedules in the 
power district, their irregularity increases and, as a result, the load density of supply centre network equipment decreases. The latter leads to a decrease in the equipment useful life, a reduction of its service life, which means that the equipment will be under repair more often and longer.

Thus, with the massive appearance of powerdeficient industrial MiniGrids, an increase in the efficiency of centralized power supply cannot be expected. The transition to this path does not ensure the achievement of goals, because in the current situation and under the established rules, industrial MiniGrids give local effects, but not systemic ones.

However, another tendency gains momentum and shows effectiveness in Russia - the emergence of balanced and redundant Energy Cells in residential areas of cities, where the main source of electricity is miniCHPPs, which are responsible for supplying energy to the population and small and medium-sized businesses in the area of their activity.

Utility Energy Cells are formed by multi-unit cogeneration plants operating on natural gas, and to reduce its consumption, it is advisable to include renewable energy plants in its composition. It makes sense to create them in power districts where there is a local shortage of electric and heat capacity and housing construction is constrained, because technological connection of new consumers is limited.

Except for distributed generation costs, Energy Cell investors often have to build their own heat and power MV and LV network and bear additional costs for them. It is obvious that Energy Cell can work independently, but their connection to RGC significantly increases power supply reliability. Besides, the integration with the regional power supply system allows co-generation units to be loaded not according to the heat schedule, but according to the electric load schedule of the power district. This reduces the payback time of investments to Energy Cell, including generating revenues from cutting off peak loads in the power district.

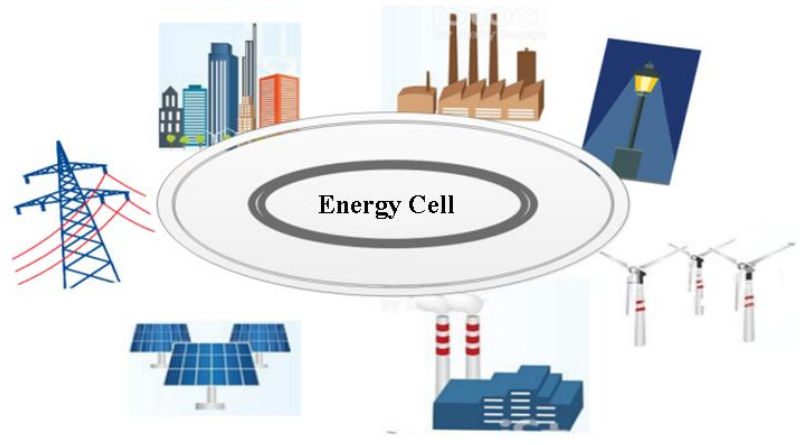

Fig. 2. Energy Cell - distributed generation facility.

Energy storage systems play an important role in Energy Cell; installation of them allows, to a certain extent, tightening the load schedule of utility consumers [11]. Low-power flow-type storage devices are most effective for this. Demand Response in Energy Cell allows redistributing the load in the daily time frame and at the same time perform the function of failure protection in LV networks.

Naturally, the main consumer in residential areas is the population and consumers equated to it. Considering that the value of the tariff for electricity and heat for the population in most regions exceeds the cost of its production at GGS and GTG, as well as in the presence of small and medium-sized businesses in the structure of energy consumption of Energy Cell, the efficiency of electricity production and transmission ensures a payback period of 5-7 years.

For example, in Novosibirsk there is a redundant Energy Cell with an electric capacity of $11 \mathrm{MW}$, where the proportion of the population is about $80 \%$. It should be noted that the installed generation capacity of this Energy Cell will increase as consumers "queue" for technological connection to Energy Cell. This competition is explained not only by the high reliability and quality of power supply, but also by the presence of low, stable and long-term price, which are not available in the retail market. This allows creating the Energy Cell energy consumption structure that corresponds to startstop and other technical characteristics of generation, carrying out targeted pricing, based on: load profile; ratio of consumed reactive and active power; requirements to uninterrupted power supply and other factors. It is to be noted that the connection of Energy Cell to the RGC networks increases the efficiency of the regional power supply system, since the last resort supplier purchases surplus electricity and capacity at a price lower than that on the wholesale market.

Currently, the process of Energy Cell creation in residential areas does not have the same pace and scale as the industrial MiniGrid, but it is with them the prospects of increasing the availability and reliability of power supply in Russia are connected. Supplying energy to the population, Energy Cell reduces the burden of cross-subsidization on industry, and in addition, attractive conditions for small and medium-sized businesses are created in residential areas. The time is ripe for the mass appearance of utility Energy Cells in 300 large and medium-sized cities of Russia, where the basis of heating systems is medium and large boiler houses that need a reconstruction.

Systemic effects - increasing the reliability and availability of power supply - will have a significant role not only for consumers in utility Energy Cells, but will reduce the load of cross-subsidization on industrial consumers, the power supply of which is advisable from centralized power systems. It is obvious that with an increase in number and capacity of utility Energy Cells, the density and uniformity of daily load schedules in the UES of Russia will increase, which will ease the problem of shortage of manoeuvrable capacities. Moreover, resource saving increases due to transfer of boiler houses to mini-CHPP. There are more than 5,000 medium and large natural gas heating plants in the country that need a reconstruction. This determines a potential for creation of mini-CHPPs and utility Energy Cells, the competitiveness of which determines their location close to consumers, which does not require the transmission of electrical energy over long distances. 


\section{Conclusions}

The reasons for the development of distributed generation in Russia significantly differ from those existing in Europe, America and other countries. The main reason for the development of the distributed electric power generation in Russia is the unsatisfactory level of regional power supply system's efficiency, which hinders the socio-economic development of the constituent entities of the Russian Federation.

Maximum systemic effects are achieved by the creation and connection to the city grids of balanced or redundant utility Energy Cells based on mini-CHP plants with an electric capacity of up to $25 \mathrm{MW}$ that supply power to the population and consumers equated with them.

With appearance of Energy Cells in residential areas and the corresponding decentralized control systems in normal and emergency conditions, we can talk about a simultaneous increase in the safety, reliability and efficiency of power supply systems. This is their advantage over other technical solutions on creation of distributed generation facilities.

It may be affirmed that favourable conditions have developed in the country, but a consistent technical policy is required to make the process of transition to distributed generation controllable, regulated and predictable.

This work was supported by the Novosibirsk State Technical University (project C20-16).

\section{References}

1. V.M. Batenin, V.V. Bushuev, N.I. Voropai, Innovative electric power industry - 21, 584 (2017)

2. A.A. Khokhlov, Yu.V. Melnikov, F.V. Veselov, D.V. Kholkin, K.A. Datsko, Distributed energy in Russia: development potential, 87 (2018)

3. S. Dzyubenko, Russian newspaper 290 (2016)

4. A.F. Dyakov Small-scale power engineering in Russia. Problems and perspectives, 128 (2003)

5. P.V. Ilyushin, Energetik, 12, 21-25 (2016)

6. V.N.Knyaginin and D.V. Kholkin Digital transition in the power industry of Russia, 47 (2017)

7. Government of the Russian Federation. (2020, Mar. $21)$, N. 320, On amendments to some acts of the Government of the Russian Federation on the functioning of active energy complexes

8. Active energy complexes [Online]. Available: http://www.soups.ru/index.php?id=press_release_view\&tx_ttnews [tt_news] $=15911 \& \mathrm{cHash}=0 \mathrm{~cd} 7 \mathrm{f} 5 \mathrm{f} 25 \mathrm{c}$ (Accessed on: Sept. 05, 2020)

9. Fuel and Energy Complex of Russia - 2019 Statistical Book [Online]. Available: https://ac.gov.ru/uploads/2-

Publications/TEK_annual/TEK.2019.pdf (Accessed on: Sept. 13, 2020)
10. D.A.Ivanovsky, Energoexpert, 3, 60-63 (2018)

11. Yano K., Hayashi S., Kumamoto T., Shibata T., Yamanishi K., SEI TECHNICAL REVIEW, 84, 2228 (2017) 